\title{
Synergistic effects of phenylhexyl isothiocyanate and LY294002 on the PI3K/Akt signaling pathway in HL-60 cells
}

\author{
HUICONG YANG ${ }^{1}$, YIQUN HUANG ${ }^{2}$, YONG ZOU ${ }^{2}$ and XUDONG MA ${ }^{2}$ \\ Departments of ${ }^{1}$ Clinical Laboratory and ${ }^{2}$ Hematology, Zhangzhou Affiliated Hospital of Fujian Medical University, \\ Zhangzhou, Fujian 363000, P.R. China
}

Received October 17, 2015; Accepted March 17, 2017

DOI: $10.3892 / 01.2017 .6556$

\begin{abstract}
The aim of the present study was to investigate the synergistic effect of phenylhexyl isothiocyanate (PHI) and LY294002 [an inhibitor of phosphoinositide 3-kinase (PI3K)] on the PI3K/protein kinase B (Akt) signaling pathway, modulating histone acetylation, inhibiting cell viability and inducing apoptosis in HL-60 cells. The inhibition of HL-60 cell viability was monitored using an MTT assay. Cell apoptosis was measured using flow cytometry. Expression of acetylated histone $\mathrm{H} 3$ and histone $\mathrm{H} 4$, and the Akt signaling pathway proteins phosphorylated Akt (p-Akt), phosphorylated mammalian target of rapamycin (p-mTOR) and phosphorylated ribosomal protein S6 kinase ( $\left.\mathrm{p}-\mathrm{p} 70^{\mathrm{S} 6 \mathrm{~K}}\right)$ was detected using western blotting. The results of the present study identified that PHI and LY294002 were able to inhibit cell viability and induce cell apoptosis in HL-60 cells. The combination exhibited a synergistic effect on cell viability and apoptosis. PHI treatment led to an accumulation of acetylated histone H3 and histone H4, but LY294002 treatment had no effect on histone acetylation. However, LY294002 was identified to enhance the effect of PHI on histone acetylation in HL-60 cells. PHI and/or LY294002 were identified to dephosphorylate proteins in the PI3K/Akt signaling pathway, with a synergistic effect observed when used in combination. The results of the present study indicated that the combination of
\end{abstract}

Correspondence to: Professor Xudong Ma, Department of Hematology, Zhangzhou Affiliated Hospital of Fujian Medical University, 59 Shengli Road, Zhangzhou, Fujian 363000, P.R. China E-mail: maxudong005@hotmail.com

Abbreviations: PHI, phenylhexyl isothiocyanate; AML, acute myeloid leukemia; DMSO, dimethyl sulfoxide; p-Akt, phosphorylated protein kinase $\mathrm{B}$; $\mathrm{p}$-mTOR, phosphorylated mammalian target of rapamycin; $\mathrm{p}-\mathrm{p} 70^{\mathrm{s} 6 \mathrm{~K}}$, phosphorylated ribosomal protein S6 kinase; HAT, histone acetyltransferase; PTEN, phosphatase and tensin homolog deleted on chromosome 10; TSA, trichostatin A; V-fluorescein isothiocyanate FITC; CI, combination index; $\mathrm{Fa}$, affected fraction

Key words: phenylhexyl isothiocyanate, LY294002, phosphoinositide 3-kinase/protein kinase B, acetylation, apoptosis
PHI and LY294002 may offer a novel therapeutic strategy for acute myeloid leukemia.

\section{Introduction}

Acute myeloid leukemia (AML) is a heterogeneous group of malignant hematopoietic disorders characterized by uncontrolled proliferation of clonally neoplastic cells and accumulation in the bone marrow of blasts with an impaired differentiation program which are inhibited at various maturation steps and are resistant to cell death (1). Intensification of chemotherapy has resulted in remission in between 70 and $85 \%$ of patients with AML; however, post-remission relapses occur frequently $(2,3)$.

The phosphoinositide 3-kinase (PI3K)/protein kinase B (Akt) signaling pathway is a key mediator of cell viability, proliferation and apoptosis. Its constitutive activation has been implicated in the pathogenesis and progression of a variety of neoplasias (4). The PI3K/Akt axis is activated in AML (5-8). The disease-free survival and overall survival times have been demonstrated to be significantly decreased in cases of AML with upregulated PI3K/Akt signaling pathway protein expression (9). The PI3K/Akt signaling pathway is crucial to diverse physiological processes that include cell cycle progression, differentiation, transcription, translation and apoptosis $(10,11)$. The PI3K/Akt signaling pathway is targeted for genomic aberrations including amplification, mutation and rearrangement more frequently than any other signaling pathway in human cancer, with the possible exception of the p53 and retinoblastoma signaling pathways. There is convincing evidence that the alterations of the PI3K/Akt signaling pathway are associated with tumor progression and resistance to radiation and systemic therapies in humans (12,13). LY294002 is an inhibitor of PI3K, which has been used extensively to investigate the role of the PI3K/Akt signaling pathway in normal and transformed cells $(14,15)$. Inactivation of PI3K using LY294002 has been demonstrated to lead to the dephosphorylation of Akt at $\mathrm{Thr}^{308}$ and $\mathrm{Ser}^{473}$, consequently inducing specific $\mathrm{G}_{1}$ phase arrest in cell proliferation and finally to apoptosis $(16,17)$. PI3K inhibitors also exhibit antitumor activity in vitro and in vivo in a variety of tumor types (18-20). Therefore, in the present study, it was investigated whether LY294002 was able to increase the sensitivity of AML cells to PHI. 
Isothiocyanates are naturally sourced compounds typically isolated from plants of the Brassicaceae family, including broccoli, cabbage, and radish. Isothiocyanates are best known for their antioxidative, anticancer chemotherapeutic, chemopreventive, and anti-angiogenic properties $(21,22)$. PHI, a synthetic isothiocyanate, is able to induce cell growth arrest and apoptosis in a number of types of tumor cell by inhibiting histone deacetylation, histone methylation and DNA methylation, and by remodeling chromatins (23-27).

In the present study, the rationale for the combined inhibition of PHI and LY294002 in HL-60 cells was investigated. Although the effect of LY294002 or PHI has been identified in a number of types of human cancer, the synergistic effect of PHI and LY294002 remains unclear.

\section{Materials and methods}

Reagents. PHI (LKT Laboratories, Inc., St. Paul, MN, USA), $>98 \%$ pure, was dissolved in $75 \%$ methanol to a stock concentration of $5 \mathrm{mmol} / \mathrm{l}$ and stored at $-20^{\circ} \mathrm{C}$ following positive pressure filtration through a $0.22 \mu \mathrm{mol} / 1 \mathrm{microporous}$ membrane filter. LY294002 (Cell Signaling Technology, Inc., Danvers, MA, USA), >99\% pure, was dissolved in dimethyl sulfoxide (DMSO) to a stock concentration of $5 \mathrm{mmol} / \mathrm{l}$. Antibodies against acetyl-histone H3 (cat. no., 06-599) and acetyl-histone H4 (cat. no., 06-866) were purchased from UpstateBiotechnology,Inc.(Lake Placid,NY,USA).Antibodies against p-Akt (cat. no., 12694), p-mTOR (cat. no., 5536) and p-p70S6K (cat. no., 9208) antibodies were purchased from Cell Signaling Technology, Inc. (Danvers, MA, USA). $\beta$-actin antibody (cat. no., sc-47778), goat anti-rabbit IgG-HRP (cat. no., sc-2004) and goat anti-mouse IgG-HRP (cat. no., sc-2005) were purchased from Santa Cruz Biotechnology, Inc. (Dallas, TX, USA). MTT (Sigma; Merck KGaA, Darmstadt, Germany) was dissolved in PBS to a working concentration of $5 \mathrm{mmol} / \mathrm{l}$.

Cell culture. The human AML cell line HL-60 was obtained from the China Center for Type Culture Collection (Beijing, China). Cells were maintained in RPMI-1640 medium supplemented with $10 \%$ heat-inactivated fetal bovine serum (both were obtained from Gibco; Thermo Fisher Scientific, Inc., Waltham, MA, USA) and maintained at $37^{\circ} \mathrm{C}$ in a humidified atmosphere containing $5 \% \mathrm{CO}_{2}$. Cells in exponential growth phase were exposed to PHI and/or LY294002 at various concentrations, as indicated for each assay. The control cultures were supplemented with the methanol-containing medium and DMSO-containing medium respectively.

Cell viability assay. MTT assay was used to analyze cell viability as described previously (28). The spectrophotometric absorbance of the samples was determined using an Ultra Multifunctional microplate reader at $490 \mathrm{~nm}$. Cells in exponential growth phase $\left(1.0 \times 10^{5}\right.$ cells $/ \mathrm{ml}$ in $\left.100 \mu \mathrm{l}\right)$ were cultured in 96-well plates with various concentrations of PHI and LY294002 $(0,10,20$ and $40 \mu \mathrm{mol} / 1$, respectively, or in combination at $20 \mu \mathrm{mol} / 1$ each). Cell viability was observed at 24, 48, 72 and $96 \mathrm{~h}$. The assay was conducted in triplicate. For evaluating the synergistic effects of the drugs, HL-60 cells were treated with $10,15,20,30$ and $40 \mu \mathrm{mol} / 1 \mathrm{PHI}$, and 10, 15, 20, 30 and $40 \mu \mathrm{mol} / 1 \mathrm{LY} 294002$ for $72 \mathrm{~h}$.
Analysis of cell apoptosis using flow cytometry. HL-60 cells were seeded at $5.0 \times 10^{5}$ cells $/ \mathrm{ml}$ in Petri dishes and cultured with the aforementioned concentrations of PHI or LY294002, or in combination, for $72 \mathrm{~h}$. An annexin V-fluorescein isothiocyanate (FITC)/PI double-fluorescence apoptosis detection kit (Kaiji Biotech, Nanjing, China) was employed to quantify the apoptosis of the HL-60 cells, according to the manufacturer's protocol. Briefly, the suspended cells were pooled, washed twice with ice-cold PBS and re-suspended in binding buffer (Kaiji Biotech, Nanjing, China) to $10^{6} / \mathrm{ml}$. Subsequently, $0.2 \mathrm{ml}$ of this cell suspension was incubated with $5 \mu \mathrm{l}$ Annexin V-FITC and $5 \mu \mathrm{l}$ PI Staining Solution for $10 \mathrm{~min}$ at room temperature in the dark. Then, samples were analyzed using a flow cytometer (BD FACSCalibur ${ }^{\mathrm{TM}}$, San Jose, CA, USA) within $1 \mathrm{~h}$. The experiment was performed in triplicate.

Western blot analysis. The protein levels were established by Western blot analysis as described previously (29). Total proteins were prepared from each culture condition with a lysis buffer containing protease inhibitors, and the lysed solution was centrifuged at $13,000 \mathrm{x}$ g for $20 \mathrm{~min}$ at $4^{\circ} \mathrm{C}$. The protein content of the lysates was determined using the Bradford protein assay. Equivalent amounts of protein $(20 \mu \mathrm{g})$ were separated were subjected to $12 \%$ SDS-PAGE and then electrotransferred onto a polyvinylidene fluoride membrane (EMD Millipore, Billerica, MA, USA). The membranes were blocked in PBS containing 5\% w/v skimmed dry milk at room temperature for $1 \mathrm{~h}$, and then incubated at $4^{\circ} \mathrm{C}$ overnight with the following antibodies: Acetyl-histone H3, acetyl-histone $\mathrm{H} 4, \mathrm{p}-\mathrm{Akt}, \mathrm{p}-\mathrm{mTOR}$ and $\mathrm{p}-\mathrm{p} 70^{\mathrm{S} 6 \mathrm{~K}}$ at the recommended dilution (1:500). Additionally, the membranes were incubated with HRP-conjugated goat anti-mouse $(1: 5,000)$ or goat anti-rabbit secondary antibodies $(1: 5,000)$ at room temperature for $1 \mathrm{~h}$. Finally, the membranes were exposed to X-ray film following use of enhanced chemiluminescence reagents (Cell Signaling Technology). Protein levels were quantified relative to $\beta$-actin as a loading control by using Image-Pro Plus v.6.0 software (IPP; Media Cybernetics, Bethesda, MD, USA), and this protocol was repeated three times.

Analysis of the combined effects of the drugs. CompuSyn software (version 2.0; ComboSyn, Inc., Paramus, NJ, USA) was used to evaluate the synergistic effects of the combination of PHI and LY294002 using to the median-effect method (30). An MTT assay was performed to determine the fraction of cells affected $(\mathrm{Fa})$. The combination index $(\mathrm{CI})$ was calculated using CompuSyn. In this analysis, the combined effect was reported as synergistic, antagonistic or additive when the $\mathrm{CI}$ value was $<1,>1$ and 1 , respectively.

Statistical analysis. Data were analyzed using SPSS statistical software (version 13.0; SPSS, Inc., Chicago, IL, USA). Results are presented as the mean \pm standard deviation from multiple independent experiments using a homogeneity test for variance and test of normality. Results were evaluated by one-way analysis of variance between groups. Multiple comparison between the groups was performed using Student Newman-Keuls method. $\mathrm{P}<0.05$ was considered to indicate a statistically significant difference. 


\section{Results}

Effects of PHI and LY294002 on HL-60 cell viability. PHI and LY294002 were identified to inhibit viability in HL-60 cells in a dose- and time-dependent manner. For instance, the viability of HL-60 cells was $97.1 \pm 2.1,84.3 \pm 2.5,57.3 \pm 2.1$ and $36.2 \pm 2.4 \%$ when treated with PHI at $0,10,20$ and $40 \mu \mathrm{mol} / 1$, respectively, for $72 \mathrm{~h}$ (Fig. 1A); the half-maximal inhibitory concentration $\left(\mathrm{IC}_{50}\right)$ was $26.19 \mu \mathrm{mol} / 1$. Similarly, the viability of HL-60 cells was $98.3 \pm 1.1,86.2 \pm 2,64.2 \pm 2.3$ and $48.7 \pm 2.0 \%$ when treated with LY294002 at 0, 10, 20 and $40 \mu \mathrm{mol} / 1$, respectively, for $72 \mathrm{~h}$ (Fig. $1 \mathrm{~B}$ ); the $\mathrm{IC}_{50}$ was $36.44 \mu \mathrm{mol} / 1$. The viability of HL-60 cells was $37.4 \pm 2.7 \%$ when treated with PHI and LY294002 in combination at $20 \mu \mathrm{mol} / 1$ each for $72 \mathrm{~h}$. However, the viability was $57.3 \pm 2.5$ and $64.2 \pm 2.3 \%$ when treated with PHI or LY294002, respectively, at $20 \mu \mathrm{mol} / 1$ separately for $72 \mathrm{~h}$ (Fig. 1C). The combination of PHI and LY294002 synergistically inhibited the viability of HL-60 cells. HL-60 cells were treated with 10, 15, 20, 30 and $40 \mu \mathrm{mol} / 1 \mathrm{PHI}$ and 10, 15, 20, 30 and $40 \mu \mathrm{mol} / 1 \mathrm{LY} 294002$ separately or in combination for $72 \mathrm{~h}$ (Fig. 1D). The CI values were $0.85635,0.87545,0.93326,0.86816$ and 0.73989 when treated with a combination of PHI and LY294002 at 10, 15, 20, 30 and $40 \mu \mathrm{mol} / 1$ (Fig. 1E). The combination of PHI and LY294002 at all concentrations exerted synergistic inhibitory effects on HL-60 cell viability.

Effects of PHI and LY294002 on apoptosis. Using flow cytometry, it was identified that the number of cells undergoing apoptosis was increased in a dose-dependent manner following exposure to PHI and/or LY294002 for $72 \mathrm{~h}$. Exposure of HL-60 cells to PHI at $0,10,20$ and $40 \mu \mathrm{mol} / 1$ for $72 \mathrm{~h}$ resulted in $1.28 \pm 0.43,8.43 \pm 1.64,15.40 \pm 2.48$ and $26.4 \pm 3.22 \%$ apoptosis, respectively. Exposure of HL-60 cells to LY294002 at 0, 10, 20 and $40 \mu \mathrm{mol} / 1$ for $72 \mathrm{~h}$ resulted in $1.28 \pm 0.43,5.43 \pm 1.34$, $12.4 \pm 1.52$ and $18.80 \pm 2.52 \%$ apoptosis, respectively. PHI and LY294002 in combination at $20 \mu \mathrm{mol} / 1$ each led to $52.7 \pm 4.51 \%$ apoptosis compared with $15.4 \pm 3.48 \%$ apoptosis for PHI alone and $12.4 \pm 1.52 \%$ apoptosis for LY294002 alone, each at $20 \mu \mathrm{mol} / \mathrm{l}$ (Fig. 2).

LY294002 enhances the effect of PHI on acetylation of histone $\mathrm{H} 3$ and H4 in HL-60 cells. Treatment with PHI led to an accumulation of acetylated histone $\mathrm{H} 3$ and $\mathrm{H} 4$. However, LY294002 had no effect on it. The acetylation of histone $\mathrm{H} 3$ and histone $\mathrm{H} 4$ was increased markedly in doseand time-dependent manner following exposure of HL-60 cells to PHI (Fig. 3A). Acetylated histone H3 was increased $1.65 \pm 0.08-, 2.96 \pm 0.14$ - and 5.21 \pm 0.24 -fold by PHI at 10 , 20 and $40 \mu \mathrm{mol} / 1$, respectively, for $72 \mathrm{~h}$ compared with the control. Acetylated histone $\mathrm{H} 4$ was increased 1.32 $\pm 0.06-$, $2.55 \pm 0.12$ - and 3.92 \pm 0.18 -fold by PHI at 10,20 and $40 \mu \mathrm{mol} / 1$, respectively, compared with the control. LY294002 was not able to alter the level of acetylation of histone $\mathrm{H} 3$ and histone H4. Acetylated histone H3 was increased 1.01 $\pm 0.04-$, $0.98 \pm 0.03$ - and 1.02 \pm 0.05 -fold by LY249002 at 10, 20 and $40 \mu \mathrm{mol} / \mathrm{l}$, respectively, for $72 \mathrm{~h}$ compared with the control. Acetylated histone H4 was increased 0.99 $\pm 0.05-, 1.03 \pm 0.05-$ and $0.97 \pm 0.04$-fold by LY249002 at 10,20 and $40 \mu \mathrm{mol} / 1$, respectively, for $72 \mathrm{~h}$ compared with the control $(\mathrm{P}>0.05$;
Fig. 3B). However, with in combination, LY294002 increased the effect that PHI exerted on histone $\mathrm{H} 3$ and histone $\mathrm{H} 4$ acetylation. Acetylated histone $\mathrm{H} 3$ and $\mathrm{H} 4$ were increased 2.96 \pm 0.14 - and 2.55 \pm 0.12 -fold by PHI alone, 3.11 \pm 0.16 - and $2.83 \pm 0.13$-fold by PHI and LY294002 in combination at $20 \mu \mathrm{mol} / 1$ each (Fig. 3C).

Synergistic effects of combined PHI and LY294002 treatment on inhibiting the PI3K/Akt signaling pathway in HL-60 cells. Levels of p-Akt, p-mTOR and p-p70 ${ }^{\mathrm{S} 6 \mathrm{~K}}$ were decreased following exposure to PHI or LY294002. When PHI was combined with LY294002, the effect was more marked.p-Akt, p-mTOR and p-p70 ${ }^{\mathrm{S} 6 \mathrm{~K}}$ levels were decreased following exposure to PHI or LY294002. Levels of p-Akt, p-mTOR and p-p70 ${ }^{\mathrm{s} 6 \mathrm{~K}}$ were increased $0.92 \pm 0.06-, 0.90 \pm 0.05-$ and $0.89 \pm 0.05$-fold, respectively, by PHI at $10 \mu \mathrm{mol} / 1,0.55 \pm 0.03-, 0.71 \pm 0.04-$ and $0.65 \pm 0.03$-fold, respectively, by PHI at $20 \mu \mathrm{mol} / 1$, and $0.42 \pm 0.02-, 0.56 \pm 0.03$ - and $0.51 \pm 0.03$-fold, respectively, by $\mathrm{PHI}$ at $40 \mu \mathrm{mol} / 1$ for $72 \mathrm{~h}$, compared with the control (Fig. 4A). Similarly, the levels of $\mathrm{p}-\mathrm{Akt}, \mathrm{p}-\mathrm{mTOR}$ and $\mathrm{p}-\mathrm{p} 70^{\mathrm{S} 6 \mathrm{~K}}$ were

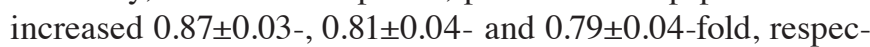
tively, by LY294002 at $10 \mu \mathrm{mol} / 1,0.51 \pm 0.03-, 0.62 \pm 0.04-$ and $0.54 \pm 0.03$-fold, respectively, by LY294002 at $20 \mu \mathrm{mol} / 1$, and $0.37 \pm 0.02-, 0.48 \pm 0.03$ - and $0.41 \pm 0.02$-fold, respectively, by LY294002 at $40 \mu \mathrm{mol} / 1$ for $72 \mathrm{~h}$, compared with the control (Fig. 4B). The levels of p-Akt, p-mTOR and p-p70 ${ }^{\mathrm{s} 6 \mathrm{~K}}$ were increased $0.81 \pm 0.03-, 0.83 \pm 0.05$ - and $0.78 \pm 0.06$-fold, respectively, by LY294002, respectively, at $20 \mu \mathrm{mol} / \mathrm{l}$ for $72 \mathrm{~h}$, and $0.65 \pm 0.03-, 0.61 \pm 0.04$ - and $0.55 \pm 0.03$-fold, respectively, by $\mathrm{PHI}$ at $20 \mu \mathrm{mol} / 1$ for $72 \mathrm{~h}$ compared with the control. However, levels of $\mathrm{p}-\mathrm{Akt}, \mathrm{p}-\mathrm{mTOR}$ and $\mathrm{p}-\mathrm{p} 70^{\mathrm{S} 6 \mathrm{~K}}$ were increased $0.37 \pm 0.04-, 0.43 \pm 0.03$ - and $0.21 \pm 0.02$-fold, respectively, by PHI and LY294002 in combination at $20 \mu \mathrm{mol} / 1$ each for $72 \mathrm{~h}$ compared with the control (Fig. 4C). The combination of PHI and LY294002 enhanced the effect on the protein levels of the PI3K/Akt signaling pathway.

\section{Discussion}

The results of the present study indicate that LY294002 and PHI induced cell apoptosis, decreased cell viability and dephosphorylated p-Akt, p-mTOR and p-p70 ${ }^{\mathrm{S} 6 \mathrm{~K}}$. Treatment with PHI led to an upregulation of histone acetylation. Our previous studies indicated that PHI induced cell apoptosis and inhibited cell viability in various tumor cell lines, including MOLT-4, PC3 and SMMC7721 cells $(23,31,32)$. These results of these studies provide evidence of the underlying molecular mechanisms for the apoptotic effects of PHI, which modulates histone acetylation, histone methylation and DNA demethylation. The results are also consistent with the evidence that PHI dephosphorylated proteins in the PI3K/Akt signaling pathway, inactivated Akt and modulated histone acetylation in PC3 cells.

Activation of the PI3K/Akt signaling pathway results in disturbance of cell proliferation and apoptosis, providing a competitive proliferative advantage for tumor cells $(4,33,34)$. It is clear that upregulation of the PI3K/Akt axis may be one of the major factors undermining successful antineoplastic treatment, thus leading to a poor prognosis in many types of cancer (35). Therefore, the PI3K/Akt pathway is an attractive 

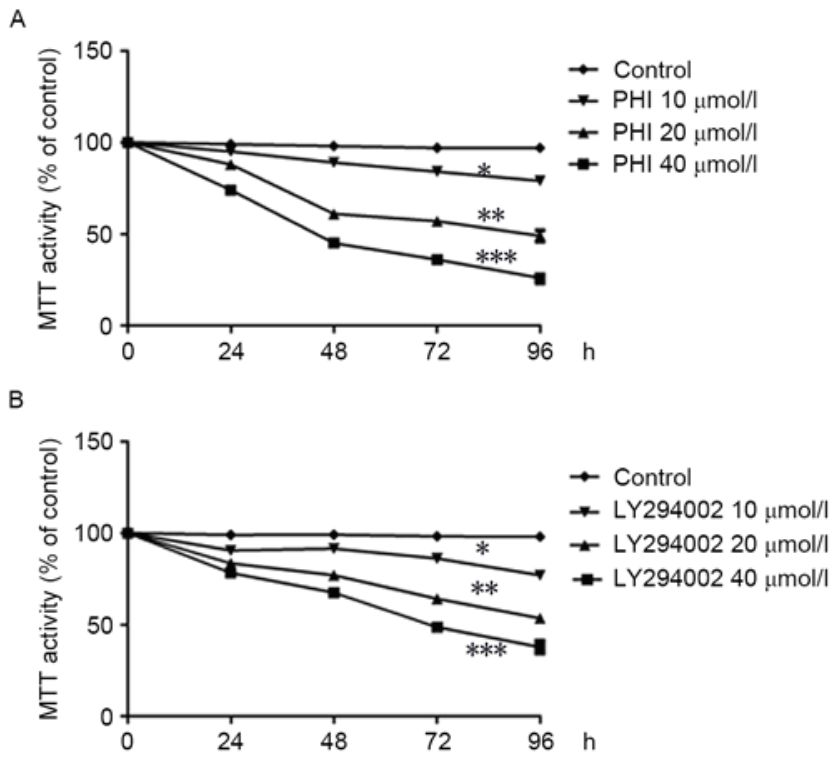

C
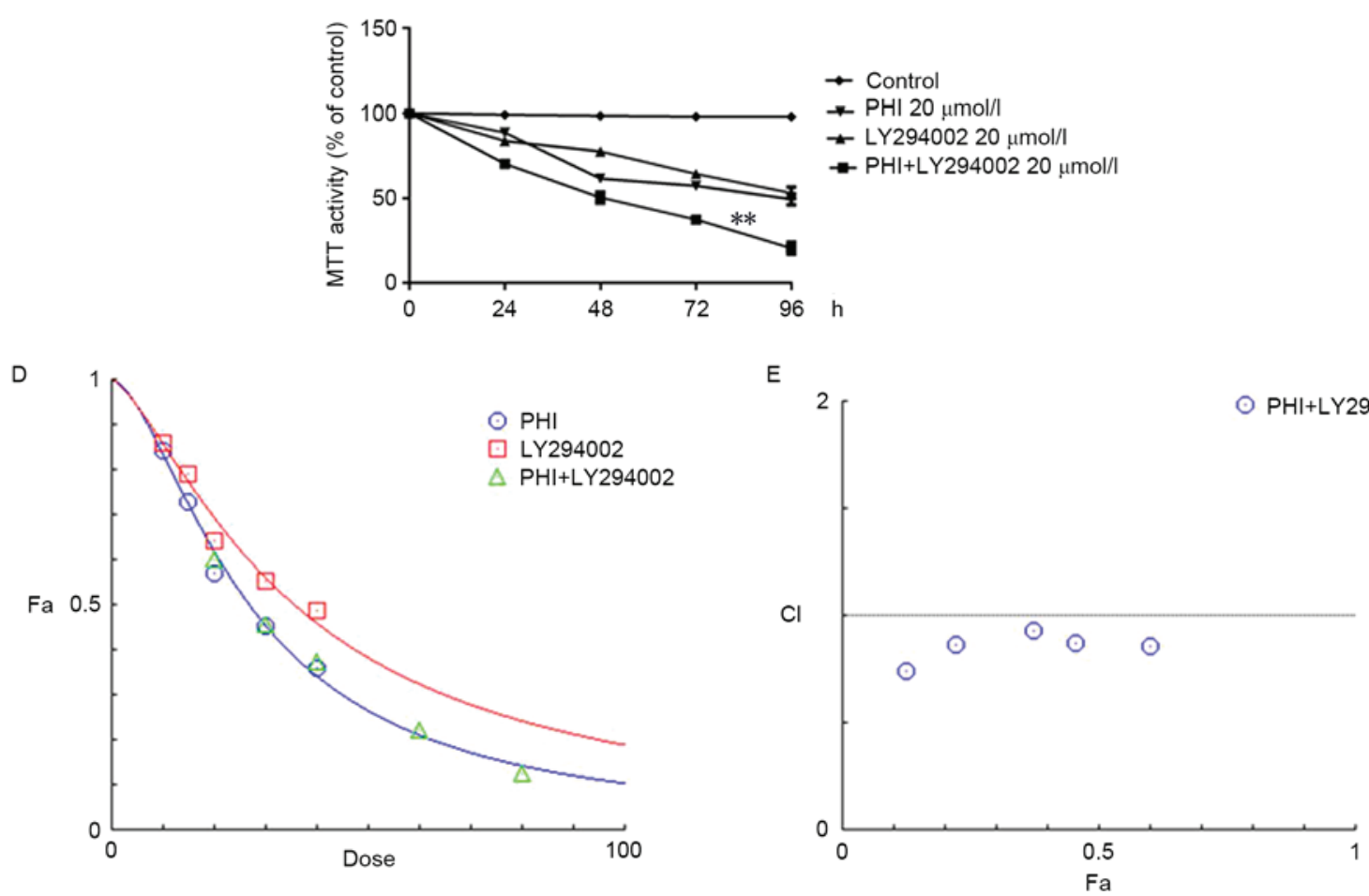

Figure 1. PHI and LY294002 inhibit the viability of HL-60 cells. (A) Cell viability was inhibited at various concentrations of PHI in a dose- and time-dependent manner vs. untreated control. (B) Cell viability was inhibited at various concentrations of LY294002 in a dose- and time-dependent manner vs. untreated control. (C) PHI and LY294002 in combination exhibited a synergistic effect on HL-60 cell viability vs. PHI or LY294002 alone. (D) Dose-response curves of the single or combined drug treatments. (E) Fa-CI curve of PHI and LY294002 in combination revealing a synergistic effect with 10, 15, 20, 30 and 40 $\mu$ mol/1 $(\mathrm{CI}<1)$. The broken line at $\mathrm{CI}=1$ represents the additive effect. ${ }^{*} \mathrm{P}<0.05,{ }^{* *} \mathrm{P}<0.01,{ }^{* * *} \mathrm{P}<0.001 ; \mathrm{Fa}$, affected fraction; $\mathrm{CI}$, combination index.

target for the development of novel therapeutic strategies in patients with various types of tumor.

LY294002, a classical PI3K inhibitor, has been used in in vitro and in vivo studies on cancer cell lines in which it induces apoptosis and increases sensitivity to chemotherapeutic drugs (36-38). The results of the present study indicated that LY294002 may induce apoptosis and inhibit viability of HL-60 cells. It inhibits the PI3K/Akt signaling pathway by dephosphorylating p-Akt, p-mTOR and $\mathrm{p}-\mathrm{p} 70^{\mathrm{s} 6 \mathrm{~K}}$.
In the present study, it was confirmed for the first time, to the best of our knowledge, that a combination of LY294002 and PHI exerts synergistic effects on inducing apoptosis and inhibiting viability of HL-60 cells. The results indicated that PHI or LY294002 resulted in an increase in the apoptotic rate and inhibition of cell viability in a dose-dependent manner. PHI and LY294002 in combination at $20 \mu \mathrm{mol} / \mathrm{l}$ each exhibited a synergistic effect with a significantly increased apoptosis rate. Treatment with PHI or LY294002 separately at $20 \mu \mathrm{mol} / 1$ for $72 \mathrm{~h}$ led to cell viability of $57.3 \pm 2.5$ and $64.2 \pm 2.3 \%$, 
A
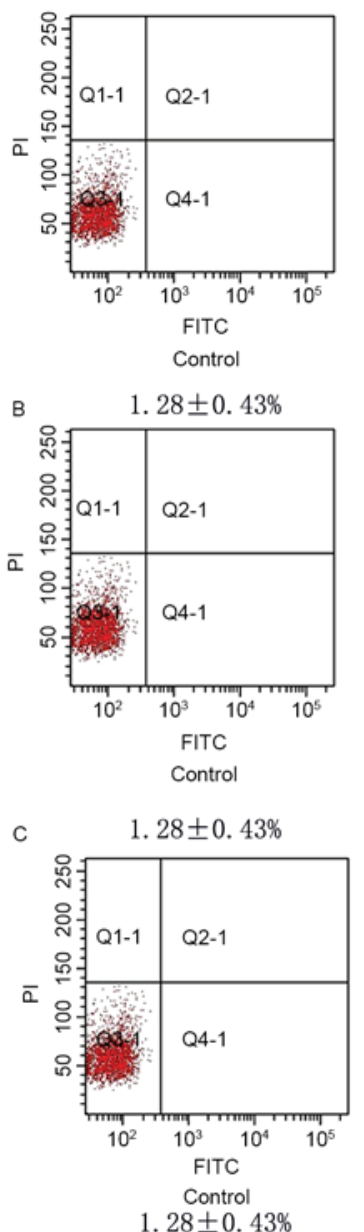

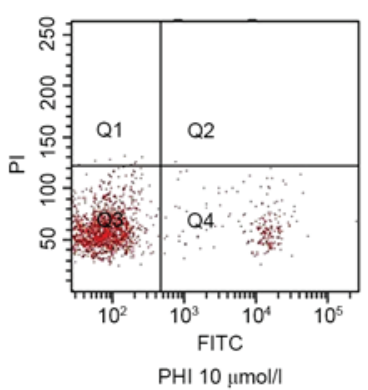

8. $43 \pm 1.64 \% *$

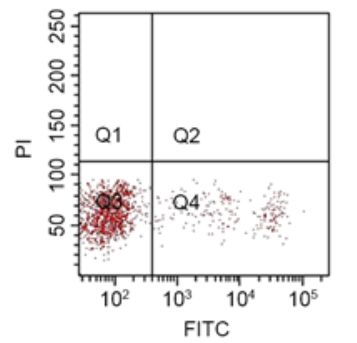

LY294002 $10 \mu \mathrm{mol} / 1$

5. $43 \pm 1.34 \% *$

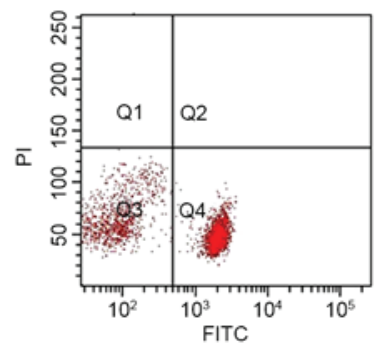

PHI+LY294002 $20 \mu \mathrm{mol} / \mathrm{l}$

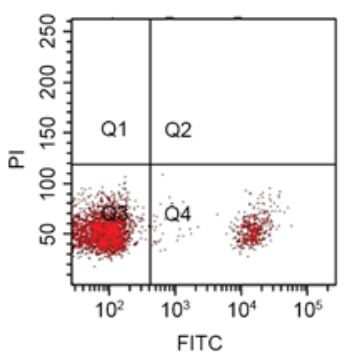

PHI $20 \mu \mathrm{mol} / \mathrm{l}$

15. $40 \pm 2.48 \% *$

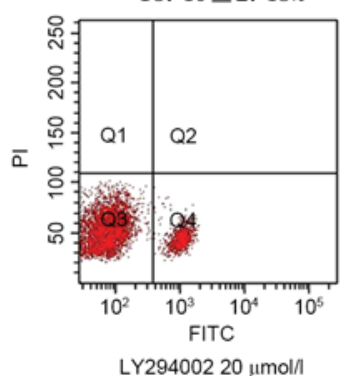

$12.4 \pm 1.52 \% *$

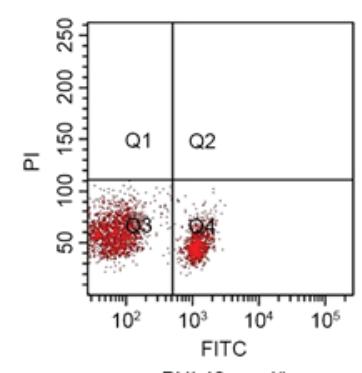

$\mathrm{PHI} 40 \mu \mathrm{mol} / \mathrm{l}$

26. $4 \pm 3.22 \%$ **

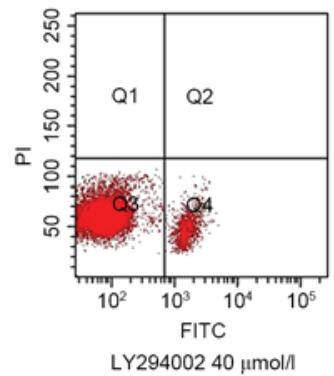

$18.80+2.52 \%$ **

Figure 2. PHI and LY294002 induce apoptosis in HL-60 cells. Fluorescence signals from annexin V-FITC and PI are reported on the $x$-axis and $y$-axis, respectively. Four quadrants represent viable (lower left), necrotic (upper right), early apoptotic (lower right) and late apoptotic (upper right) cells. The rate of apoptosis of the cells is presented in the figure. (A) Apoptosis was increased gradually following treatment with PHI at 10,20 and $40 \mu$ mol/1 for $72 \mathrm{~h}$ in HL-60 cells vs. untreated control. (B) Apoptosis was increased gradually following treatment with LY294002 at 10,20 and $40 \mu$ mol/1 for 72 h in HL-60 cells vs. untreated control. (C) PHI and LY294002 in combination significantly increased apoptosis in HL-60 cells vs. PHI or LY294002 alone. * $<<0.05$, ${ }^{* *} \mathrm{P}<0.01$,

${ }^{* * *} \mathrm{P}<0.001$; FITC, fluorescein isothiocyanate; PI, propidium iodide; Q, quadrant.

respectively, compared with the control. PHI and LY294002 in combination at $20 \mu \mathrm{mol} / 1$ each exhibited a synergistic effect with a significantly increased inhibition of cell viability. Investigation into the underlying molecular mechanism indicated that PHI induced an accumulation of acetylated histone H3 and histone H4 in HL-60 cells; however, LY294002 exhibited no effect on histone acetylation. However, upregulation of acetylated histone $\mathrm{H} 3$ and histone $\mathrm{H} 4$ was increased by PHI in combination with LY294002 compared with PHI alone. These results indicated that LY294002 may enhance the effect of PHI on histone acetylation. PHI and LY294002 each dephosphorylated $\mathrm{p}$-Akt; in combination, they resulted in a synergistic effect, dephosphorylating p-Akt further.

Akt synergistically enhanced the activity of histone acetyltransferases (HATs), inducing p300, and the increasing the binding capacity with the HAT p300/cyclic adenosine 5'-monophosphate-response element-binding protein-binding protein (CBP)-associated factor (39). Rapamycin inhibition of the mTOR signaling pathway may lead to the release of the oncogene Esal from the ribosomal protein gene promoter and lead to histone $\mathrm{H} 4$ deacetylation, thereby affecting gene expression (40). Resistance to histone deacetylase inhibitors in non-small cell lung cancer is mediated in part through the activation of nuclear factor- $\kappa \beta$ through the phosphatidylinositol 3-kinase/Akt-dependent pathway (41). A number of studies (42-44) have indicated that the dynamic changes of histone modification may regulate mTOR signaling pathway protein kinase activity. However, the underlying molecular mechanism remains unknown. A study by Gan and Zhang (45) identified that the activation of phosphatase and tensin homolog deleted on chromosome 10 (PTEN), and Akt phosphorylation was downregulated by trichostatin A (TSA) treatment. This study demonstrated that downregulation of Akt phosphorylation induced by TSA may be mediated by PTEN small interfering RNA. It has been identified that the phosphorylation of Akt at $\operatorname{Ser}^{1834}$ enhances the transcriptional activity of p300 by increasing promoter recruitment and histone acetylation (39). Chromatin immunoprecipitation assays revealed that CBPs and nuclear factor erythroid 2-related factor (Nrf2) recruitment to the antioxidant-response element (ARE) and broad complex-tramtrack-bric-a-brac and cap'n'collar homology 1 release were inhibited by LY294002, along with the partial inhibition of Nrf2 nuclear accumulation (46). Furthermore, acetylation of histone H3 at Lys ${ }^{9}$ and 

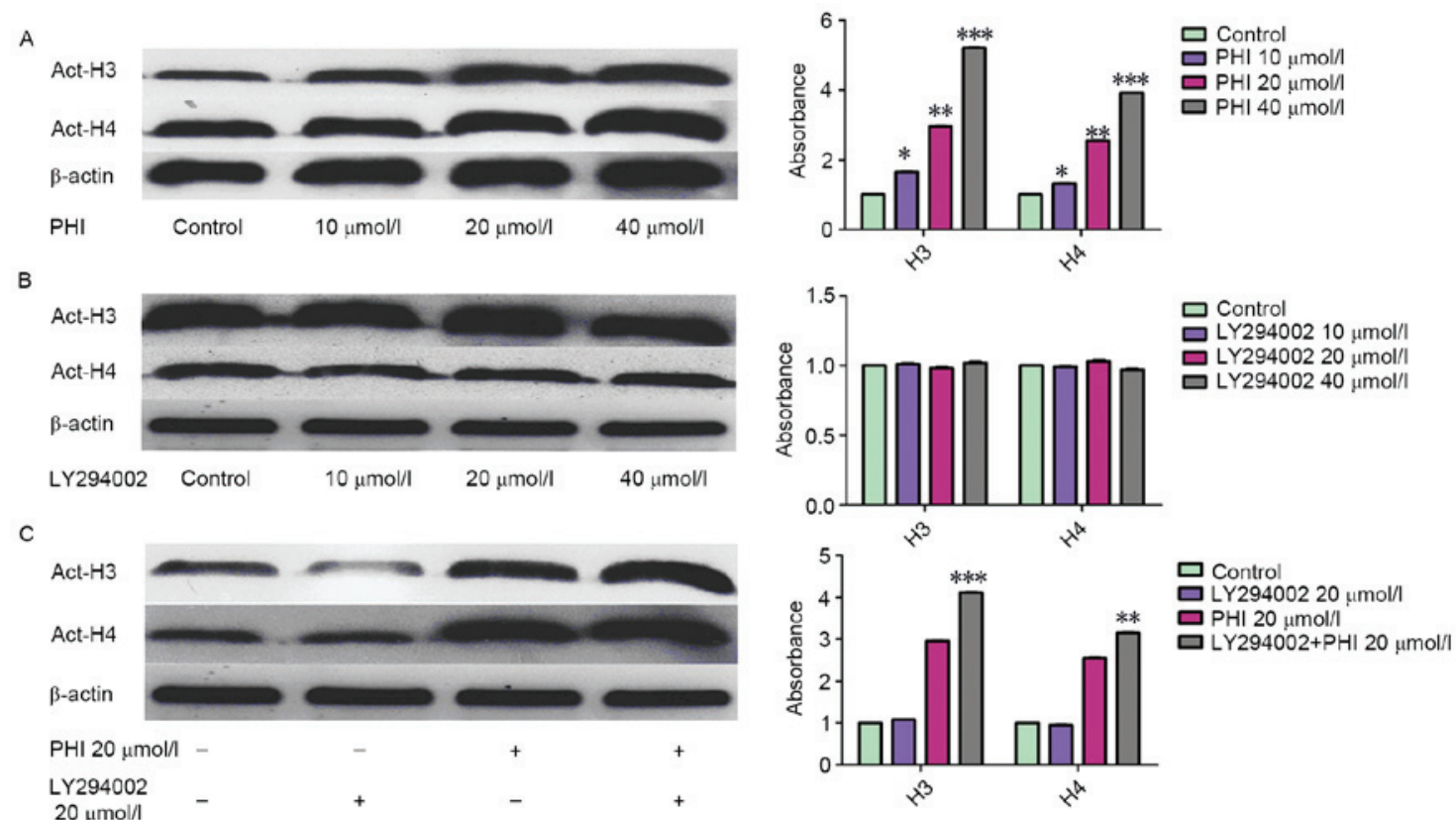

Figure 3. PHI, but not LY294002, promotes acetylation of histone H3 and histone H4 in HL-60 cells; however, PHI in combination with LY294002 enhances acetylation. (A) PHI at 10, 20 and $40 \mu \mathrm{mol} / 1$ for $72 \mathrm{~h}$ upregulated acetylated histone $\mathrm{H} 3$ and histone $\mathrm{H} 4$ in a concentration-dependent manner in HL-60 cells vs. untreated control. (B) LY294002 at 10, 20 or $40 \mu \mathrm{mol} / 1$ exhibited no effect on levels of acetylated histone $\mathrm{H} 3$ and histone $\mathrm{H} 4 \mathrm{vs.} \mathrm{untreated} \mathrm{control.} \mathrm{(C)} \mathrm{PHI}$ and LY294002 in combination increases the upregulation of acetylated histone $\mathrm{H} 3$ and histone $\mathrm{H} 4$ levels vs. PHI alone. ${ }^{*} \mathrm{P}<0.05,{ }^{* * *} \mathrm{P}<0.01,{ }^{* * * *} \mathrm{P}<0.001 ;$ Act-H, acetylated histone.

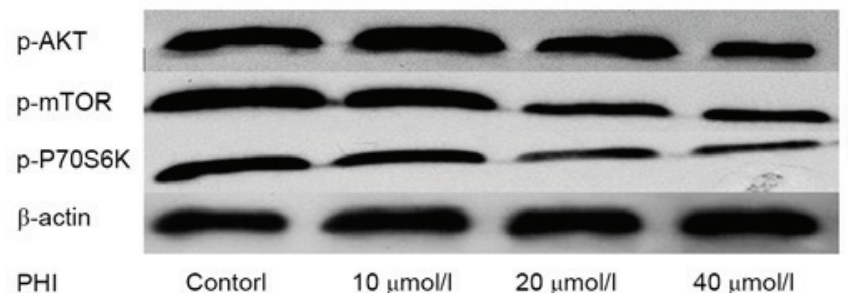

B

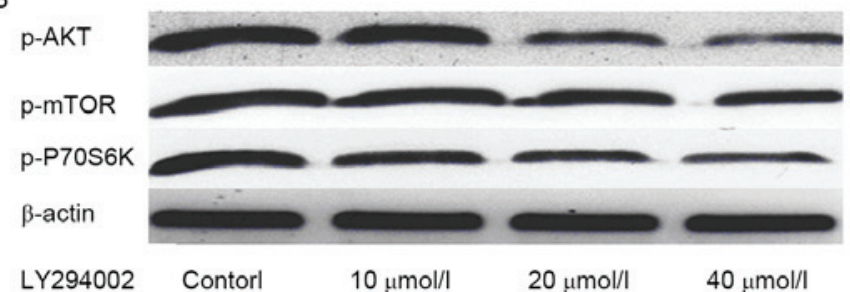

C

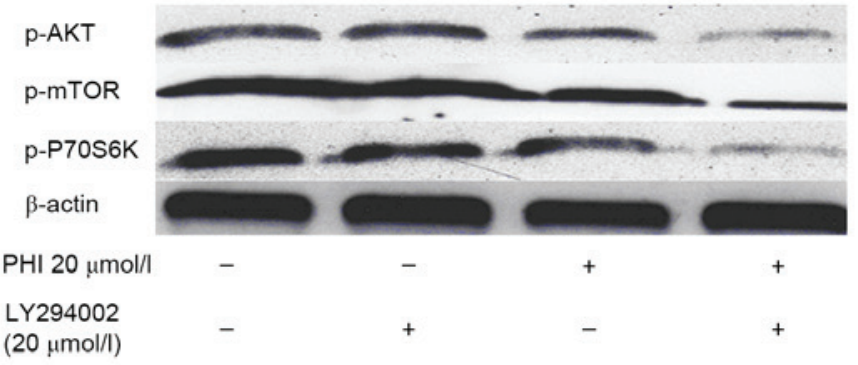

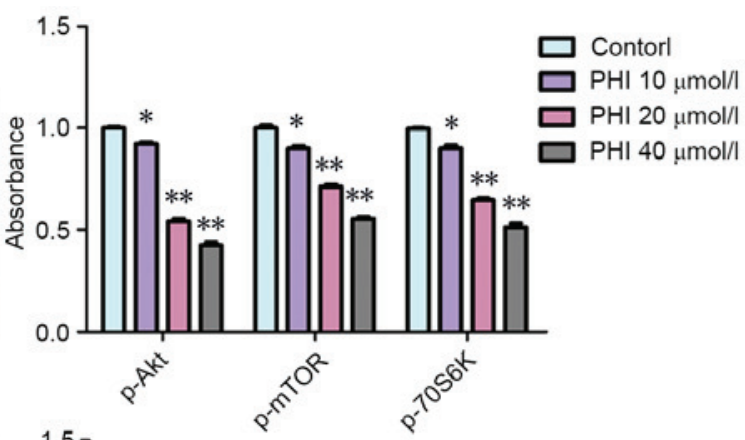
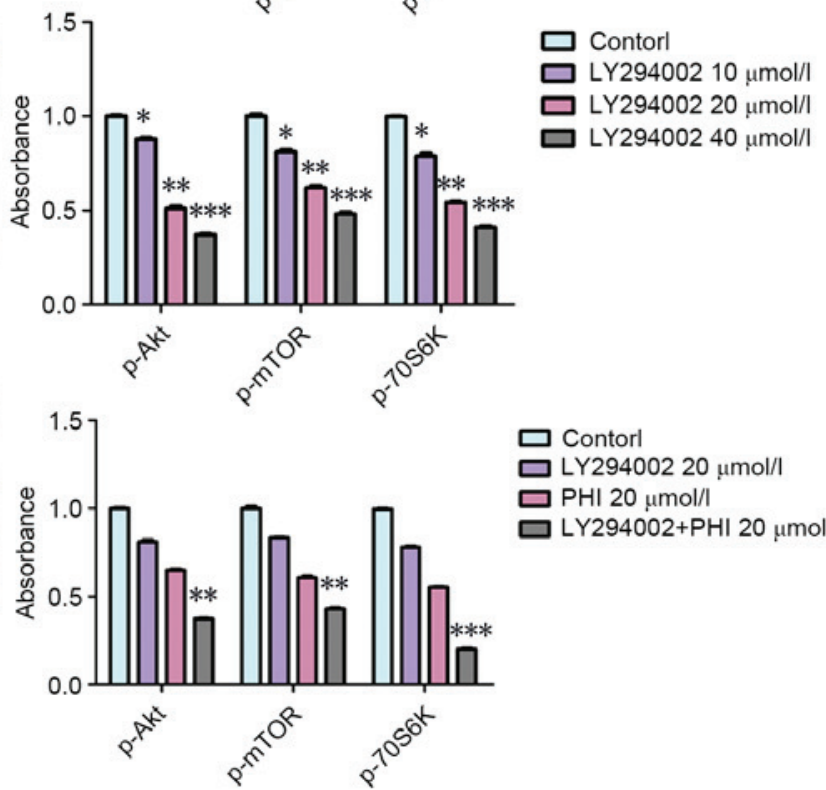

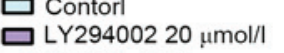

口 $\mathrm{PHI} 20 \mu \mathrm{mol} / \mathrm{I}$

口 LY294002+PHI $20 \mu \mathrm{mol} / \mathrm{l}$

Figure 4. PHI and LY294002 dephosphorylate proteins in the PI3K/Akt signaling pathway in HL-60 cells. (A) PHI dephosphorylated p-Akt, p-mTOR and p-p70 $0^{\mathrm{s} 6 \mathrm{~K}}$ in a dose-dependent manner vs. untreated control. (B) LY294002 dephosphorylated p-Akt, p-mTOR and p-p70 ${ }^{\mathrm{s} 6 \mathrm{~K}}$ in a dose-dependent manner vs. untreated control. (C) PHI and LY294002 in combination enhanced the dephosphorylation of p-Akt, p-mTOR and p-p70 ${ }^{\mathrm{S} 6 \mathrm{~K}}$ vs. PHI or LY294002 alone. ${ }^{*} \mathrm{P}<0.05,{ }^{* *} \mathrm{P}<0.01,{ }^{* * *} \mathrm{P}<0.001$. 
Lys $^{18}$, and deacetylation histone $\mathrm{H} 3$ at $\mathrm{Lys}^{14}$ were associated with PI3K-dependent ARE activation. Apoptosis induced by doxorubicin, an inhibitor of the PTEN signaling pathway, was enhanced by TSA. Furthermore, TSA promoted early growth response protein 1 (Egr-1) expression, which is the major transcription factor of PTEN, and this resulted in upregulation of PTEN expression, which consequently potentiated apoptosis (47). HAT p300 was able to synergistically activate PTEN transcription with Egr-1, implicating the role of histone acetylation in the regulation of PTEN expression.

The results of the present study suggest that a combination of PHI and LY294002 may be a novel treatment for acute leukemia.

\section{Acknowledgements}

The present study was partly supported by a grant-in-aid from the Foundation of Science and Technology of Zhangzhou, Fujian, China (grant no. Z07014), the Foundation of Science and Technology of Fujian Medical University, Fujian, China (grant no. FZS08018), the Science Research Foundation of the Ministry of Health, and United Fujian Provincial Health, and Education Project for Tackling Key Research, China (grant no. WKJ2008-2-55).

\section{References}

1. Löwenberg B, Downing JR and Burnett A: Acute myeloid leukemia. N Engl J Med 341: 1051-1062, 1999.

2. Wolff SN, Herzig RH, Fay JW, Phillips GL, Lazarus HM, Flexner JM, Stein RS, Greer JP, Cooper B and Herzig GP: High-dose cytarabine and daunorubicin as consolidation therapy for acute myeloid leukemia in first remission: Long-term follow-up and results. J Clin Oncol 7: 1260-1267, 1989.

3. Wells RJ, Woods WG, Buckley JD, Odom LF, Benjamin D, Bernstein I, Betcher D, Feig S, Kim T, Ruymann F, et al: Treatment of newly diagnosed children and adolescents with acute myeloid leukemia: A Childrens cancer group study. J Clin Oncol 12: 2367-2377, 1994.

4. Bellacosa A, Kumar CC, Di Cristofano A and Testa JR: Activation of AKT kinases in cancer: Implications for therapeutic targeting. Adv Cancer Res 94: 29-86, 2005.

5. Kubota Y, Ohnishi H, Kitanaka A, Ishida T and Tanaka T: Constitutive activation of PI3K is involved in the spontaneous proliferation of primary acute myeloid leukemia cells: Direct evidence of PI3K activation. Leukemia 18: 1438-1440, 2004.

6. Min YH, Eom JI, Cheong JW, Maeng HO, Kim JY, Jeung HK, Lee ST, Lee MH, Hahn JS and Ko YW: Constitutive phosphorylation of Akt/PKB protein in acute myeloid leukemia: Its significance as a prognostic variable. Leukemia 17: 995-997, 2003.

7. Xu Q, Simpson SE, Scialla TJ, Bagg A and Carroll M: Survival of acute myeloid leukemia cells requires PI3 Kinase activation. Blood 102: 972-980, 2003.

8. Zhao S, Konopleva M, Cabreira-Hansen M, Xie Z, Hu W, Milella M, Estrov Z, Mills GB and Andreeff M: Inhibition of phosphatidylinositol 3-kinase dephosphorylates BAD and promotes apoptosis in myeloid leukemias. Leukemia 18: 267-275, 2004.

9. Stauffer F, Holzer P and García-Echeverria C: Blocking the $\mathrm{PI} 3 \mathrm{~K} / \mathrm{PKB}$ pathway in tumor cells. Curr Med Chem Anticancer Agents 5: 449-462, 2005.

10. Brazil DP, Yang ZZ and Hemmings BA: Advances in protein kinase B signalling: AKTion on multiple fronts. Trends Biochem Sci 29: 233-242, 2004.

11. Hanada M, Feng J and Hemmings BA: Structure, regulation and function of PKB/AKT-a major therapeutic target. Biochim Biophys Acta 1697: 3-16, 2004.

12. Edlind MP and Hsieh AC: PI3K-AKT-mTOR signaling in prostate cancer progression and androgen deprivation therapy resistance. Asian J Androl 16: 378-386, 2014.
13. Wang P, Liu N, Pang Q, Qu C, Wang B and Guo H: PI3K/AKT signaling pathway in the regulation of non-small cell lung cancer radiosensitivity after hypofractionated radiation therapy. Int J Radia Oncol Biol Physics 84 (Suppl): S670, 2012.

14. Roche S, Koegl M and Courtneidge SA: The phosphatidylinositol 3-kinase alpha is required for DNA synthesis induced by some, but not all, growth factors. Proc Natl Acad Sci USA 91: 9185-9189, 1994.

15. Shivakrupa R, Bernstein A, Watring $\mathrm{N}$ and Linnekin $\mathrm{D}$ : Phosphatidylinositol 3'-kinase is required for growth of mast cells expressing the kit catalytic domain mutant. Cancer Res 63: 4412-4419, 2003.

16. Bondar VM, Sweeney-Gotsch B, Andreeff M, Mills GB and McConkey DJ: Inhibition of the phosphatidylinositol 3'-kinase-AKT pathway induces apoptosis in pancreatic carcinoma cells in vitro and in vivo. Mol Cancer Ther 1: 989-997, 2002.

17. Hu H, Jiang C, Li G and Lü J: PKB/AKT and ERK regulation of caspase-mediated apoptosis by methylseleninic acid in $\mathrm{LNCaP}$ prostate cancer cells. Carcinogenesis 26: 1374-1381, 2005.

18. Schultz RM, Merriman RL, Andis SL, Bonjouklian R, Grindey GB, Rutherford PG, Gallegos A, Massey K and Powis G: In vitro and in vivo antitumor activity of the phosphatidylinositol-3-kinase inhibitor, wortmannin. Anticancer Res 15: 1135-1139, 1995.

19. Hu L, Zaloudek C, Mills GB, Gray J and Jaffe RB: In vivo and in vitro ovarian carcinoma growth inhibition by a phosphatidylinositol 3-kinase inhibitor (LY294002). Clin Cancer Res 6: 880-886, 2000

20. Semba $S$, Itoh $N$, Ito $M$, Harada $M$ and Yamakawa $M$ : The in vitro and in vivo effects of 2-(4-morpholinyl)-8-phenyl-chromone (LY294002), a specific inhibitor of phosphatidylinositol 3'-kinase, in human colon cancer cells. Clin Cancer Res 8: 1957-1963, 2002.

21. Minarini A, Milelli A, Fimognari C, Simoni E, Turrini E and Tumiatti V: Exploring the effects of isothiocyanates on chemotherapeutic drugs. Expert Opin Drug Metab Toxicol 10: 25-38, 2014.

22. Cavell BE, Syed Alwi SS, Donlevy A and Packham G: Anti-angiogenic effects of dietary isothiocyanates: Mechanisms of action and implications for human health. Biochem Pharmacol 81: 327-336, 2011.

23. Ma X, Fang Y, Beklemisheva A, Dai W, Feng J, Ahmed T, Liu D and Chiao JW: Phenylhexyl isothiocyanate inhibits histone deacetylases and remodels chromatins to induce growth arrest in human leukemia cells. Int J Oncol 28: 1287-1293, 2006.

24. Xiao L, Huang Y, Zhen R, Chiao JW, Liu D and Ma X: Deficient histone acetylation in acute leukemia and the correction by an isothiocyanate. Acta Haematol 123: 71-76, 2010.

25. Huang YQ, Ma XD, Zhen RJ, Chiao JW and Liu DL: Experiment study of PHI on histone methylation and acetylation in Molt-4 cells. Zhonghua Xue Ye Xue Za Zhi 28: 612-615, 2007 (In Chinese).

26. Jiang S, Ma X, Huang $Y, X u$ Y, Zheng $R$ and Chiao JW: Reactivating aberrantly hypermethylated $\mathrm{p} 15$ gene in leukemic $\mathrm{T}$ cells by a phenylhexyl isothiocyanate mediated inter-active mechanism on DNA and chromatin. J Hematol Oncol 3: 48, 2010.

27. Zou Y, Ma X, Huang Y, Hong L and Chiao JW: Effect of phenylhexyl isothiocyanate on aberrant histone $\mathrm{H} 3$ methylation in primary human acute leukemia. J Hematol Oncol 5: 36, 2012

28. Chiarini F, Del Sole M, Mongiorgi S, Gaboardi GC, Cappellini A, Mantovani I, Follo MY, McCubrey JA and Martelli AM: The novel Akt inhibitor, perifosine, induces caspase-dependent apoptosis and downregulates P-glycoprotein expression in multidrug-resistant human T-acute leukemia cells by a JNK-dependent mechanism. Leukemia 22: 1106-1116, 2008.

29. Wang L, Liu D, Ahmed T, Chung FL, Conaway C and Chiao JW: Targeting cell cycle machinery as a molecular mechanism of sulforaphane in prostate cancer prevention. Int J Oncol 24: 187-192, 2004.

30. Chou TC: Theoretical basis, experimental design, and computerized simulation of synergism and antagonism in drug combination studies. Pharmacol Rev 58: 621-681, 2006.

31. Beklemisheva AA, Fang Y, Feng J, Ma X, Dai W and Chiao JW: Epigenetic mechanism of growth inhibition induced by phenylhexyl isothiocyanate in prostate cancer cells. Anticancer Res 26: 1225-1230, 2006.

32. Lai YD, Ma XD, Huang YQ, Xu XN, Wang XZ, Chiao DJ and Liu D: Modulation of histone acetylation and induction of apoptosis in SMMC-7721 cells by phenylhexyl isothiocyanate. Zhonghua Zhong Liu Za Zhi 32: 804-807, 2010 (In Chinese). 
33. Osaki M, Oshimura M and Ito H: PI3K-Akt pathway: Its functions and alterations in human cancer. Apoptosis 9: 667-676, 2004.

34. Zhuang Z, Ma X, Huang Y, Zheng Z, Zheng Y and Jiang S: Study on histone acetylation modulation and Akt signaling pathway inhibition by phenyhexyle isothiocyanate in prostate cancer PC3 cell line. Chin J Urol 31: 707-709, 2010.

35. Kim D, Dan HC, Park S, Yang L, Liu Q, Kaneko S, Ning J, $\mathrm{He}$ L, Yang H, Sun M, et al: AKT/PKB signaling mechanisms in cancer and chemoresistance. Front Biosci 10: 975-987, 2005.

36. West KA, Castillo SS and Dennis PA: Activation of the PI3K/Akt pathway and chemotherapeutic resistance. Drug Resist Updat 5 : 234-248, 2002.

37. Martelli AM, Tabellini G, Bortul R, Tazzari PL, Cappellini A Billi AM and Cocco L: Involvement of the phosphoinositide 3 -kinase/Akt signaling pathway in the resistance to therapeutic treatments of human leukemias. Histol Histopathol 20: 239-252, 2005.

38. Luo J, Manning BD and Cantley LC: Targeting the PI3K-Akt pathway in human cancer: Rationale and promise. Cancer Cell 4: 257-262, 2003.

39. Huang WC and Chen CC: Akt phosphorylation of p300 at Ser-1834 is essential for its histone acetyltransferase and transcriptional activity. Mol Cell Biol 25: 6592-6602, 2005.

40. Rohde JR and Cardenas ME: The tor pathway regulates gene expression by linking nutrient sensing to histone acetylation. Mol Cell Biol 23: 629-635, 2003.
41. Denlinger CE, Rundall BK and Jones DR: Inhibition of phosphatidylinositol 3-kinase/Akt and histone deacetylase activity induces apoptosis in non-small cell lung cancer in vitro and in vivo. J Thorac Cardiovasc Surg 130: 1422-1429, 2005.

42. Wang X, Sun DF and Fang JY: Research advances on the relationship of PI3-kinase/Akt/mTOR pathway and epigenetic modification. Yi Chuan 28: 1585-1590, 2006 (In Chinese).

43. Wei FZ, Cao Z, Wang X, Wang H, Cai MY, Li T, Hattori N, Wang D, Du Y, Song B, et al: Epigenetic regulation of autophagy by the methyltransferase EZH2 through an MTOR-dependent pathway. Autophagy 11: 2309-2322, 2015.

44. Nishioka C, Ikezoe T, Yang J, Koeffler HP and Yokoyama A: Blockade of mTOR signaling potentiates the ability of histone deacetylase inhibitor to induce growth arrest and differentiation of acute myelogenous leukemia cells. Leukemia 22: 2159-2568, 2008.

45. Gan YH and Zhang S: PTEN/AKT pathway involved in histone deacetylases inhibitor induced cell growth inhibition and apoptosis of oral squamous cell carcinoma cells. Oral Oncol 45: e150-e154, 2009.

46. Sakamoto K, Iwasaki K, Sugiyama H and Tsuji Y: Role of the tumor suppressor PTEN in antioxidant responsive element-mediated transcription and associated histone modifications. Mol Biol Cell 20: 1606-1617, 2009.

47. Pan L, Lu J, Wang X, Han L, Zhang Y, Han S and Huang B: Histone deacetylase inhibitor trichostatin a potentiates doxorubicin-induced apoptosis by up-regulating PTEN expression. Cancer 109: 1676-1688, 2007. 